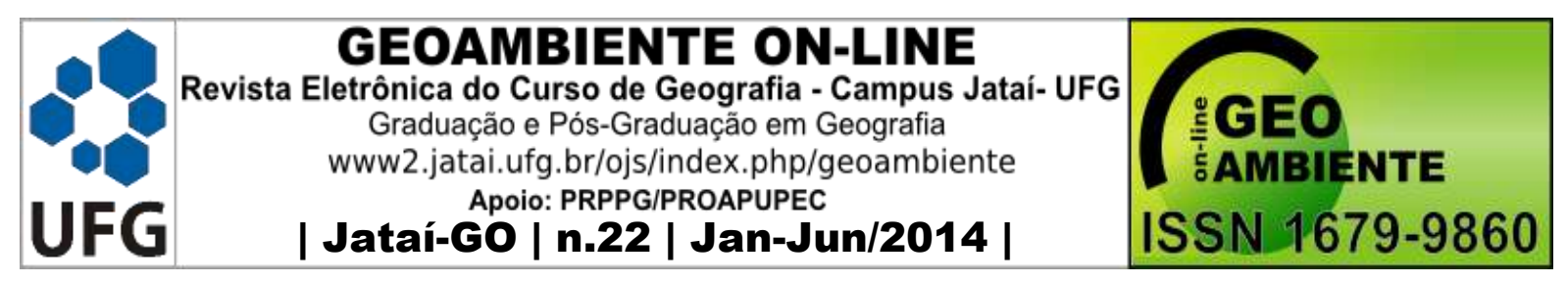

\title{
BALANÇOS ENERGÉTICOS DA PRODUÇÃO DE ETANOL PARA DIFERENTES MATÉRIAS PRIMAS
}

Lucas Mendes Oliveira ${ }^{\mathbf{1}}$, Juan Carlos Valdés Serra ${ }^{\mathbf{2}}$, Karine Beraldo Magalhães Oliveira' (1 - Instituto Federal do Tocantins - IFTO, lucasmendes@ifto.edu.br, karine@ifto.edu.br, 2 Universidade Federal do Tocantins - UFT, email, juancs@uft.edu.br)

\section{Resumo}

A utilização do álcool etílico como combustível é apontada hoje como uma das principais alternativas energéticas para o futuro, em substituição aos combustíveis fósseis, que, além de não serem renováveis, geram vários problemas ambientais. Da mesma forma que todo recurso energético, o etanol demanda energia para sua produção. Nesse sentido, o objetivo deste trabalho consiste em estudar o balanço energético da produção de etanol para as diferentes matérias primas. Foram identificadas algumas das principais matérias primas utilizadas na produção de etanol (cana-de-açúcar, milho, mandioca e resíduos celulósicos) e descritos os processos envolvidos na sua obtenção. Em seguida, foram analisados os principais balanços energéticos da produção de etanol encontrados na literatura, para as diferentes matériasprimas. Os resultados obtidos demonstram que a cana-de-açúcar, dentre as culturas agrícolas analisadas, apresenta balanço energético positivo destacado, sendo que o aproveitamento dos resíduos agrícolas pode aumentar a energia líquida obtida com a produção de etanol todas às outras culturas analisadas.

Palavras-chave: Produção de etanol; balanço energético; matérias primas.

\section{Abstract \\ ENERGETIC BALANCE OF ETHANOL PRODUCTION FOR DIFERENTS RAW MATERIALS}

The use of ethyl alcohol as fuel is pointed to today as one of the most important energy alternatives for the future, replacing fossil fuels, which are not renewable and generate various environmental problems. In the same way that all energy resource, energy is demanded for

\footnotetext{
Artigo recebido para publicação em 05 de Abril de 2012 Artigo aprovado para publicação em 18 de Junho de 2014
} 


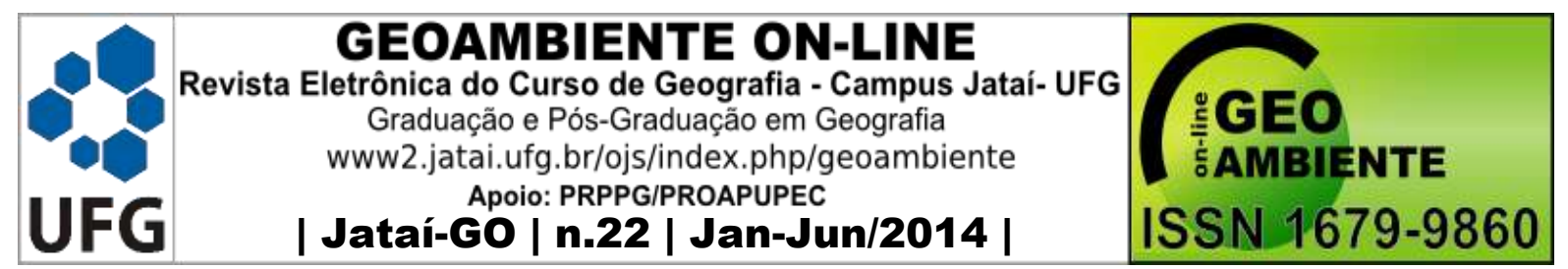

ethanol production. In this sense, the purpose of this paper is to study the energy balance of ethanol production for the different raw materials. To this end, the main raw material used in the alcohol's production (sugar cane, maize, cassava and cellulosic residues) was identified and the processes involved in obtaining it was described. Then, it was analyzed the main energy balances of ethanol production found in the literature, to the different raw materials. The results obtained demonstrate that, for analyzed crops, sugar cane, agricultural crops is analyzed was the one that presents more positive energy balance, and that the use of agricultural residues can increase net energy gained with ethanol production for all cultures.

Keywords: ethanol production; energy balance; raw materials.

\section{Resumen}

\section{BALANCE ENERGÉTICO DE LA PRODUCCIÓN DE ETANOL PARA DIFERENTES MATERIAS PRIMAS}

El uso de alcohol etílico como combustible es apuntado hoy como una alternativa importante de energía para el futuro, como sustituto de los combustibles fósiles que no son renovables y pueden generar muchos problemas ambientales. Similar a todos los recursos energéticos, el etanol demanda de una energía para su producción. En este sentido, el objetivo de este trabajo es estudiar el balance energético de la producción de etanol para diferentes materias primas que se utilizan para la su obtención. Fueron levantadas las principales materias primas utilizadas en la producción de etanol (caña de azúcar, maíz, yuca y residuos de celulosas), describiendo así los procesos que intervienen en su obtención. Seguidamente fueron analizados los balances de energía de la producción de etanol encontrados en publicaciones para las diferentes materias primas. Los resultados obtenidos demuestran caña de azúcar, dentro de las materias primas analizadas, es la que presenta un balance de energía positiva y que el uso de residuos agrícolas puede aumentar la energía neta adquirida con la producción de etanol para las otras culturas analizadas.

Palabras clave: Producción de etanol; balance de energía; materias primas.

\section{INTRODUÇÃO}

O ser humano necessita de energia para sua sobrevivência e realização das atividades econômicas, e vem, ao longo dos anos, desenvolvendo tecnologias que visam uma melhoria na sua qualidade de vida, o que acarreta um maior consumo de energia. No entanto, a maior 


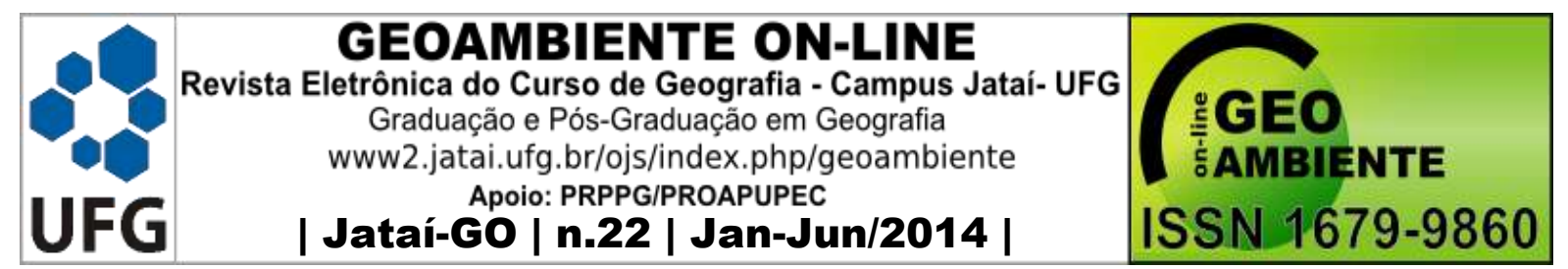

parte da energia consumida no planeta é proveniente da queima de combustíveis fósseis, principalmente petróleo, gás natural e carvão. De acordo com Lucon \& Goldemberg (2009), em 2006, 81\% da energia utilizada no mundo se originaram desse tipo de combustível. Esses compostos, mais especificamente o petróleo e o carvão, são responsáveis por grande parte das emissões de dióxido de carbono $\left(\mathrm{CO}_{2}\right)$ para a atmosfera, o que é considerada a principal causa do aquecimento global, além de outros gases poluentes, como o dióxido de enxofre $\left(\mathrm{SO}_{2}\right)$, precursor do trióxido de enxofre $\left(\mathrm{SO}_{3}\right)$ e do $\mathrm{H}_{2} \mathrm{SO}_{4}$, causadores da chuva ácida; do monóxido de carbono $(\mathrm{CO})$ e dos óxidos de nitrogênio $\left(\mathrm{NO}_{\mathrm{x}}\right)$, que são gases tóxicos e que formam o chamado "smog fotoquímico" (BRAGA et. al., 2005).

Por não serem renováveis, esses combustíveis inevitavelmente se esgotarão no futuro, o que torna imperativa a busca por novas fontes de energia que sejam renováveis e possam sustentar a sociedade industrial. Essas fontes podem ser hidráulica, eólica ou ainda a biomassa, que pode ser utilizada para queima direta o ainda convertida em outros biocombustíveis, como o etanol (álcool combustível) e o biodiesel. No Brasil, o álcool já se tornou uma alternativa consolidada, principalmente com a difusão dos motores do tipo flexfuel, que podem utilizar tanto álcool quanto gasolina em veículos.

Assim como qualquer recurso energético, a produção do etanol consome energia. Para se saber se um combustível é viável do ponto de vista energético, é necessário fazer seu balanço energético. Apesar disso, para Urquiaga et al. (2005) apud Salla et al. (2010) pouca atenção vem sendo dada aos estudos do balanço energético. Nesse sentido, o objetivo do presente trabalho analisar o balanço energético da produção de etanol para as diferentes matérias-primas.

\section{DISCUSSÃO CRÍTICA}

\subsection{Balanço energético}

Balanço energético é o parâmetro que verifica a quantidade de energia fóssil investida e a energia obtida através dos processos de produção do combustível (OLIVEIRA, 2010). Seu valor é dado pela relação entre a energia obtida com o combustível e a energia gasta na sua produção. Valores superiores a 1 significam que a energia obtida é maior que a energia gasta, portanto, o balanço é positivo e a fonte viável, entretanto, valores inferiores a 1 mostram que se gasta mais energia para produzir o combustível do que se pode obter com a sua utilização, o que torna o balanço energético negativo. Segundo Soetaert \& Vandamme (2009), para 


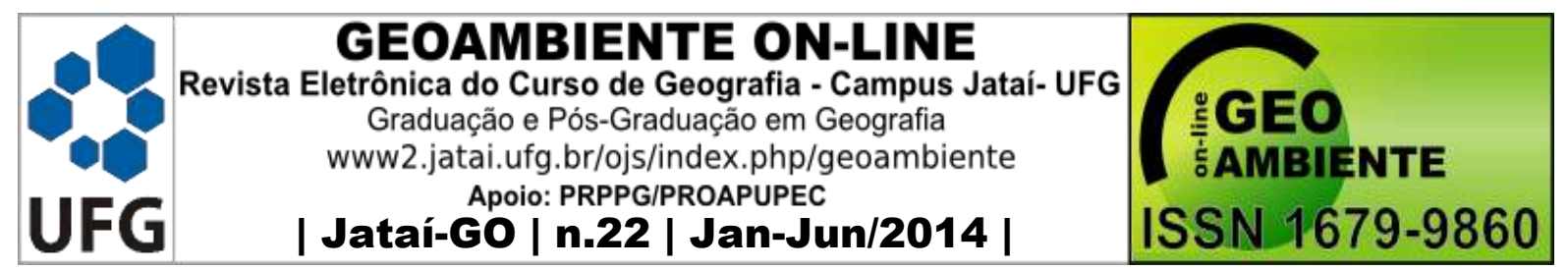

produtos derivados de culturas agrícolas, como o etanol, é necessário levar em conta os gastos energéticos para o cultivo da planta, transporte e para o processo produtivo.

\subsection{Matérias primas utilizadas na produção de etanol}

São várias as matérias primas utilizadas na produção de etanol, que segundo Macedo (1993), podem ser divididas em três categorias: Entre os produtos chamados sacaríneos, assim conhecidos por possuírem o açúcar sacarose, que dá origem ao álcool, podemos citar: canade-açúcar, sorgo sacarino (colmo), beterraba, sucos de frutas em geral, entre outros. Em relação aos amiláceos, que possuem esse nome por conterem amido, temos a mandioca, cereais de um modo geral, sorgo (grãos), batata e babaçu (mesocarpo). A outra categoria é a de matérias primas celulósicas, na qual o etanol é produzido a partir da celulose existente em sua composição, na qual se destacam: eucalipto, marmeleiro, serragem, bagaço de cana, pericarpo de babaçu, casca de arroz, entre outros.

Segundo Marcoccia (2007), a cana-de-açúcar é a matéria prima mais utilizada em países da América latina e na Austrália. Já nos EUA e no Canadá predomina a produção de etanol a partir do milho, assim como a beterraba açucareira na Europa (França, Alemanha e Espanha). Mandioca, trigo e sorgo são mais utilizados nos países asiáticos, sendo que se produz etanol a partir do sorgo também na África, e na Suécia utilizam-se restos florestais.

\subsection{Processo de produção do etanol}

O processo de obtenção da matéria prima é diferente para cada cultura. Já o processo de obtenção de álcool, a partir de biomassa, pode ser dividido em quatro grandes fases: preparação da matéria-prima; obtenção do substrato para fermentação; fermentação e destilação. As duas primeiras fases apresentam diferenças substanciais com relação a cada um dos três grandes grupos de produtos a serem processados (sacaríneos, amiláceos e celulósicos), enquanto as duas últimas, para todos eles, podem ser consideradas praticamente idênticas, (MACEDO, 1993).

A figura 1 apresenta o fluxograma genérico de uma usina de produção de açúcar e álcool, a partir da cana-de-açúcar (matéria sacarínea) de acordo com Macedo (2005).

No que diz respeito às matérias amiláceas, a figura 2 apresenta um fluxograma adaptado da produção de etanol a partir de fontes amiláceas, segundo Pereira Júnior, Ferreira \& Alves (2004). Nota-se que, no caso das matérias primas amiláceas, são necessárias duas 


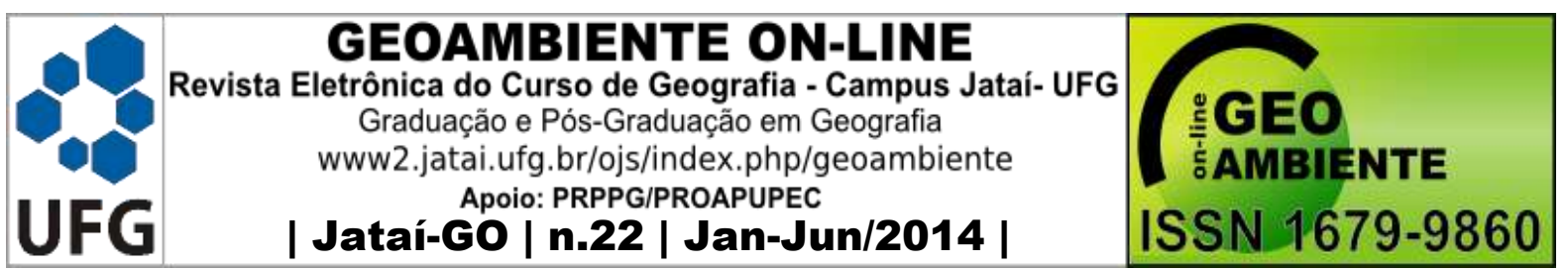

etapas a mais, a pré-sacarificação e a sacarificação, isso se deve ao fato de o amido não ser diretamente conversível em etanol, o que torna imperativo que o mesmo seja convertido em açúcar antes da fermentação, essas etapas são feitas utilizando-se enzimas.

Figura 1 - Fluxograma de uma usina de produção de açúcar e álcool.

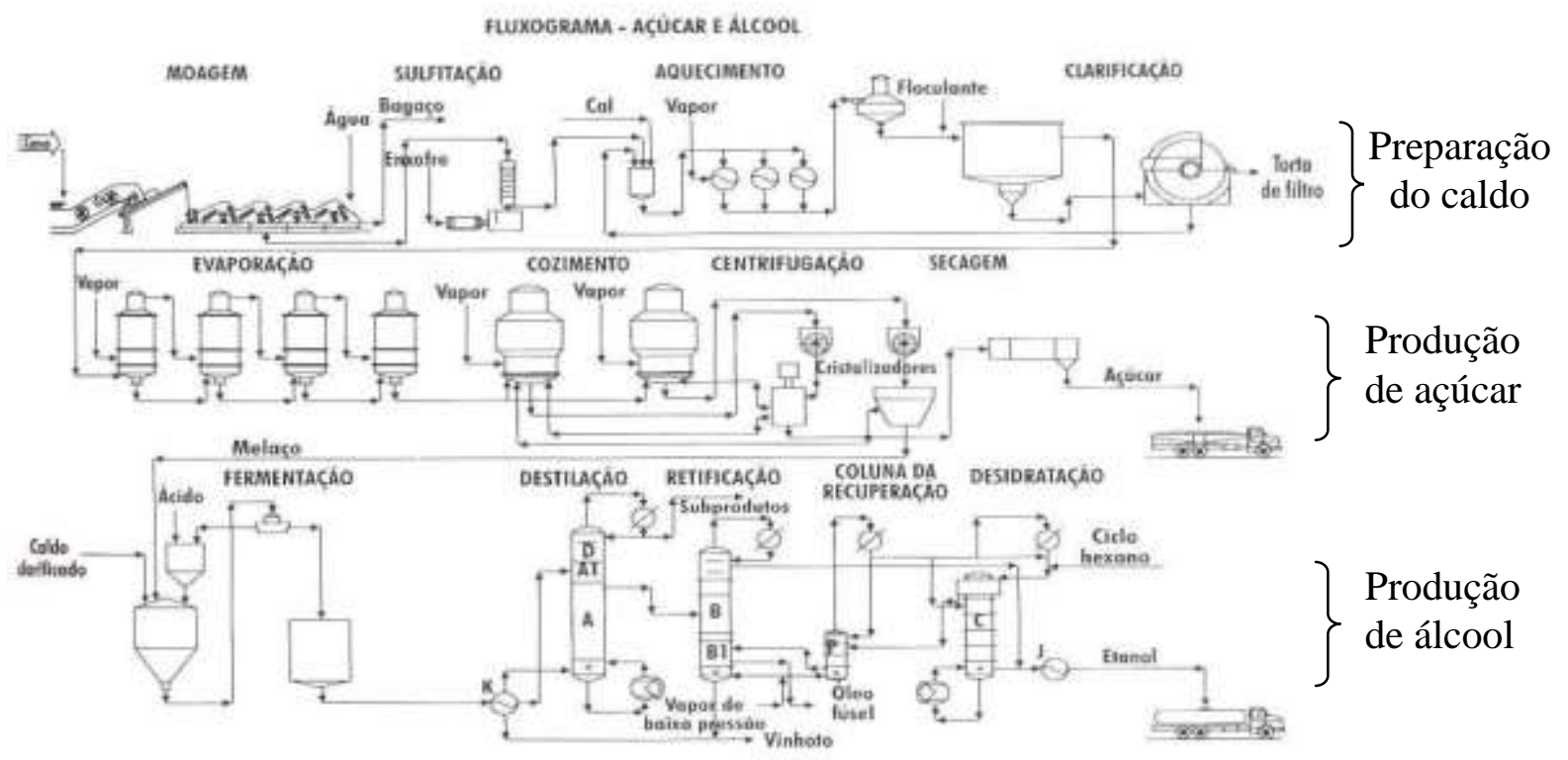

Fonte: Adaptado de Macedo (2005, p. 251).

Figura 2 - Fluxograma da produção de álcool a partir da batata-doce.

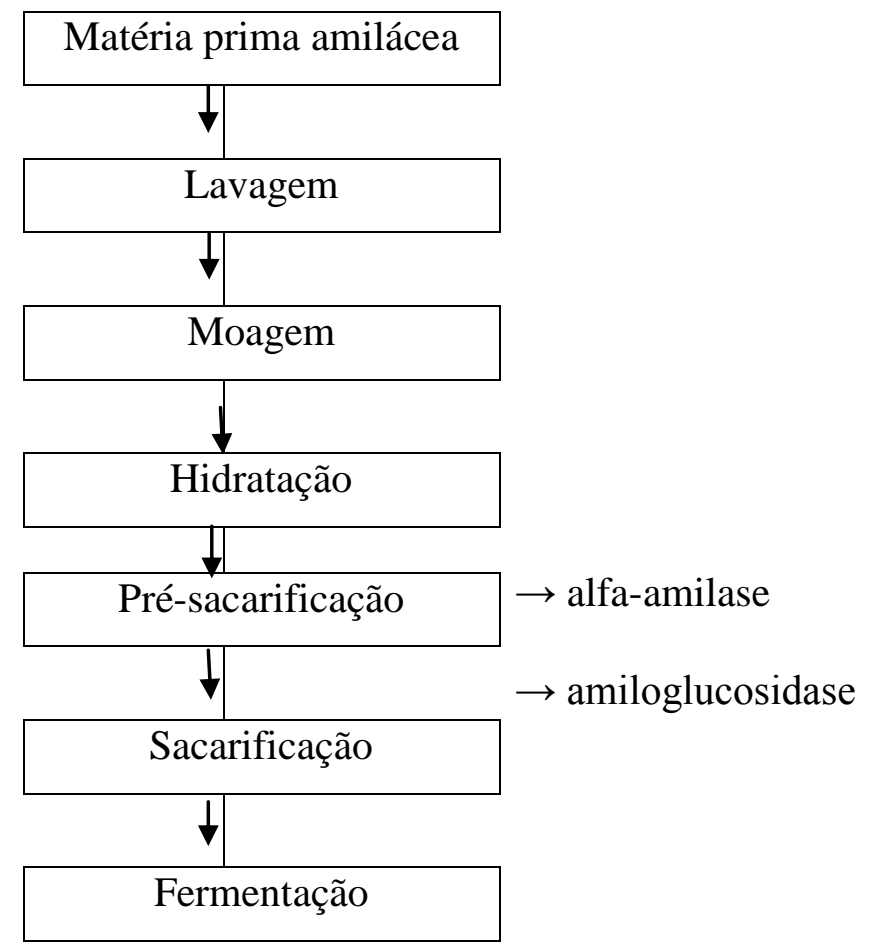



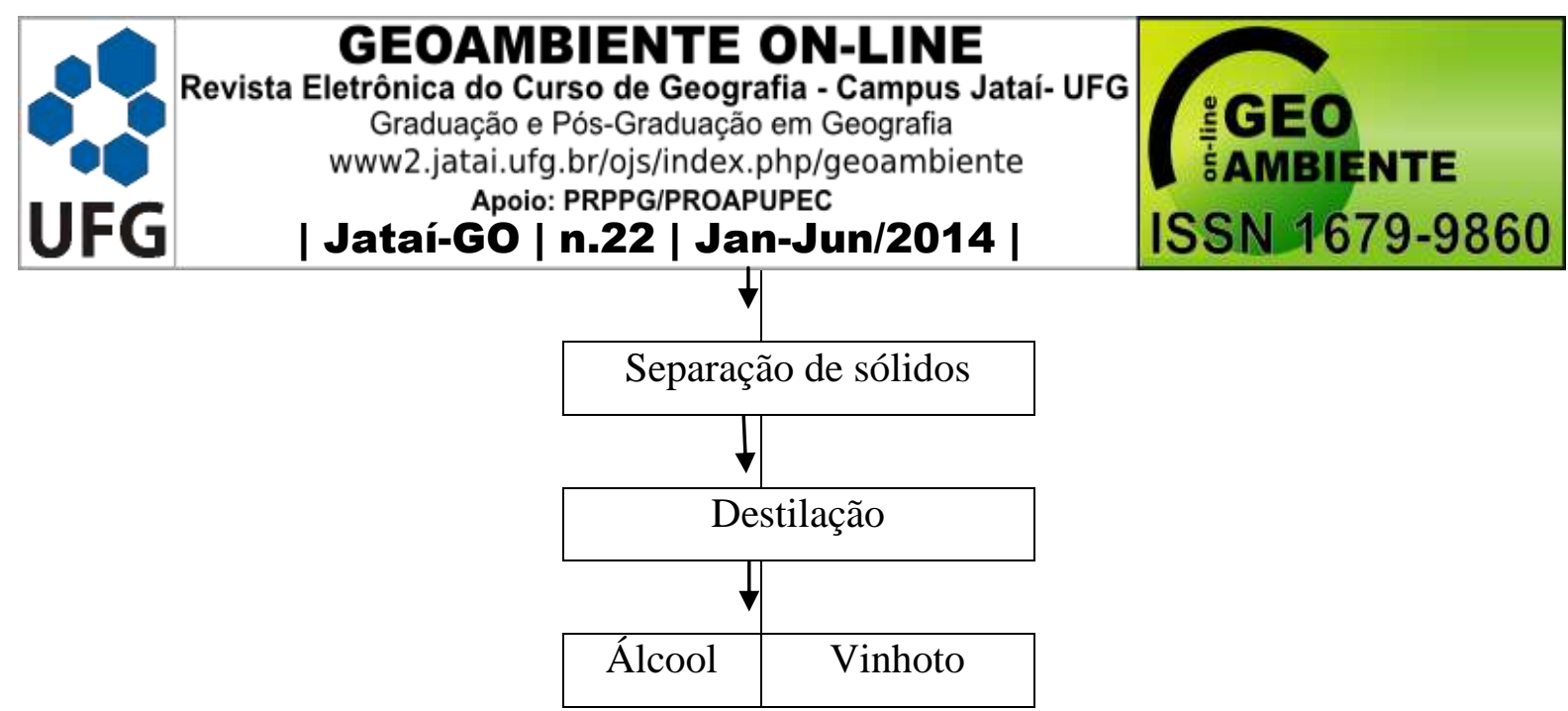

FONTE: Pereira Júnior, Ferreira \& Alves (2004) com adaptações.

De acordo com Macedo (1993), no caso dos materiais celulósicos, também é necessário converter a celulose em sacarose antes da fermentação, isso pode ser feito utilizando-se também a via enzimática ou a via ácida. Obviamente, essas etapas adicionais exigem um gasto energético maior para produção de etanol a partir desses materiais, em detrimento das matérias primas sacaríneas.

\section{MATERIAIS E MÉTODOS}

Primeiramente antes de analisar o balanço energético em um sistema de produção, determina-se a energia gasta na produção, neste caso, na obtenção do etanol. As atividades consumidoras de energia na produção de etanol, são diversas, resumidamente encontram-se dividas em:

A) Na produção agrícola:

$\checkmark$ Produção, transporte e aplicação de fertilizantes e defensivos agrícolas;

$\checkmark$ Mão-de-obra;

$\checkmark$ Máquinas agrícolas;

$\checkmark$ Transporte da matéria prima.

B) No processo de produção:

$\checkmark$ Edificações;

$\checkmark$ Produção e transporte de equipamentos;

$\checkmark$ Eletricidade;

$\checkmark$ Mão-de-obra;

$\checkmark \quad$ Transporte entre as fases de produção;

$\checkmark$ Calor para destilação;

$\checkmark$ Transporte do produto até o consumidor. 


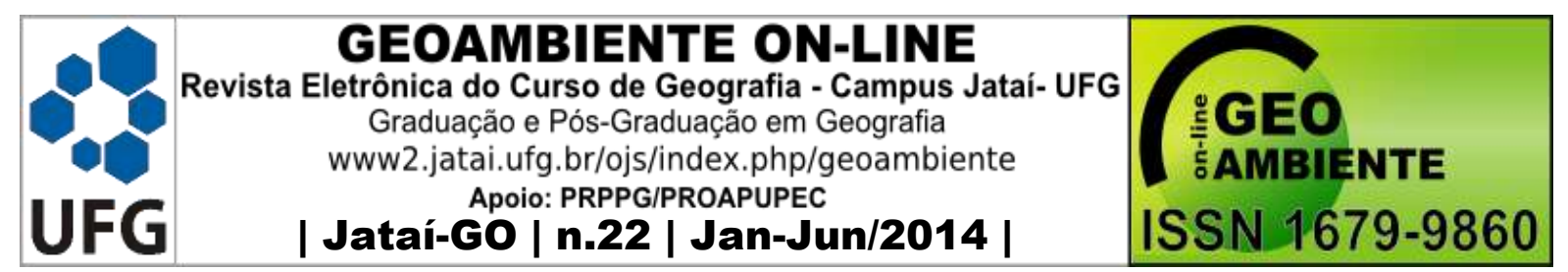

A análise dos balanços energéticos da produção de álcool para as diferentes matérias primas foi feita baseando-se em dados secundários, por meio de consultas à literatura sobre o assunto e a trabalhos já realizados na área. Para os materiais sacaríneos a cultura escolhida para o balanço energético foi a cana-de-açúcar, pois é a mais utilizada no Brasil, e para os celulósicos foi escolhido o bagaço de cana, por ser um co-produto do setor sucroalcooleiro do Brasil. Em relação às matérias primas amiláceas, foram pesquisados os balanços energéticos do milho, por ser a cultura predominante na produção de etanol nos Estados Unidos, maior produtor mundial, e da mandioca, por ser, dentre os respectivos materiais, aquele que apresenta maior desenvolvimento no que diz respeito à produção de álcool combustível no Brasil.

\section{RESULTADOS E DISCUSSÃO}

\subsection{Balanço energético do etanol da cana-de-açucar}

Em seu trabalho realizado em microdestilarias no sul de Minas Gerais, Santos \& Santos (2009) quantificaram a energia gasta para produção da cana em Kcal por Tonelada de cana $(\mathrm{kcal} / \mathrm{TC})$ para as fases agrícolas e industriais. A tabela 1 mostra os resultados obtidos pelos autores para a fase agrícola. As atividades identificadas pelos autores como consumidoras de energia foram: operações agrícolas; transportes; aplicação de calcário, fertilizantes e herbicidas; movimentação de máquinas, como tratores e caminhões; confecção de mudas e utilização de implementos agrícolas. O total de energia gasta por tonelada de cana foi de $66.438 \mathrm{kcal}$.

Tabela 1 - Gasto energético no setor agrícola para obtenção do etanol a partir da cana-deaçúcar.

\begin{tabular}{c|c}
\hline Atividade & Energia consumida por tonelada de cana (kcal) \\
\hline Processos agrícolas & 5.869 \\
\hline Transportes & 2.087 \\
\hline Fertilizantes (NPK) & 25.784 \\
\hline Calcário & 2.938 \\
\hline Herbicidas & 3.489 \\
\hline Mudas & 1.787 \\
\hline Caminhões e Tratores & 20.658 \\
\hline Implementos & 3.826 \\
\hline Total & 66.438 \\
\hline
\end{tabular}

Fonte: Santos \& Santos (2009) com adaptações

$\mathrm{Na}$ tabela 2 podem-se observar os gastos energéticos na fase industrial para a obtenção de etanol a partir da cana-de-açúcar. Nessa fase, os gastos energéticos foram ainda maiores, 


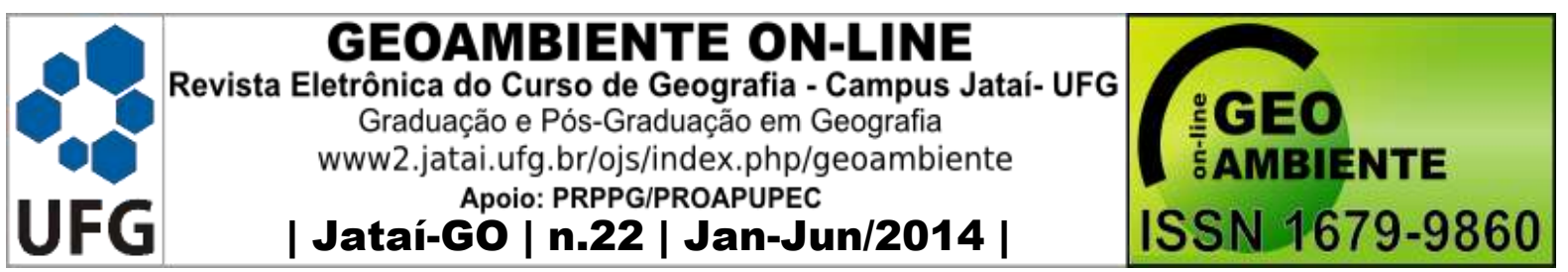

totalizando $90.022 \mathrm{kcal}$ por tonelada de cana moída. As atividades identificadas como consumidoras de energia foram: queima de lenha na caldeira; utilização de eletricidade nas atividades industriais e administrativas; uso de lubrificantes; construção e manutenção de edificações; e aquisição e manutenção dos equipamentos.

Tabela 2 - Gasto energético no setor industrial para obtenção do etanol a partir da cana-de-açúcar.

\begin{tabular}{c|c}
\hline Atividade & Energia consumida por tonelada de cana (kcal) \\
\hline Queima de lenha & 19.433 \\
\hline Energia elétrica & 19.074 \\
\hline Lubrificantes & 170 \\
\hline Edificações & 35.239 \\
\hline Equipamentos pesados & 11.634 \\
\hline Equipamentos Leves & 4.472 \\
\hline Total & 90.022 \\
\hline
\end{tabular}

Fonte: Santos \& Santos (2009) com adaptações

Percebe-se que, segundo os autores, o gasto total de energia para produção de etanol de uma tonelada de cana-de-açúcar é 157.547 kcal. Os mesmos consideraram uma produção de 85 litros de etanol por tonelada de cana, o que geraria $383.394 \mathrm{kcal}$ de energia pelo etanol e $79.160 \mathrm{kcal}$ pelo bagaço, que pode ser utilizado para queima, logo, com uma tonelada de cana-de-açúcar é possível se produzir 462.554 kcal. Fazendo a relação entre energia obtida e energia gasta, temos um balanço energético de 3,15.

Já Oliveira (2010), calculou o balanço energético da cana-de-açúcar e encontrou o valor de 8,3. Enquanto Grego (2011) realizou um trabalho de comparação entre os balanços energéticos do etanol da cana e do milho e encontrou um balanço positivo para a cana-deaçúcar de 9,4.

García et al. (2011) em seu trabalho realizado no México utilizando o método do ciclo de vida para calcular o balanço energético da produção de etanol a partir da cana-de-açúcar naquele país, obteve uma quantidade de energia de 4,8GJ para cada GJ investido na produção, ou seja, um balanço energético de 4,8 .

A figura 3 apresenta um gráfico com a comparação entre os balanços energéticos encontrados para a cana-de-açúcar. 


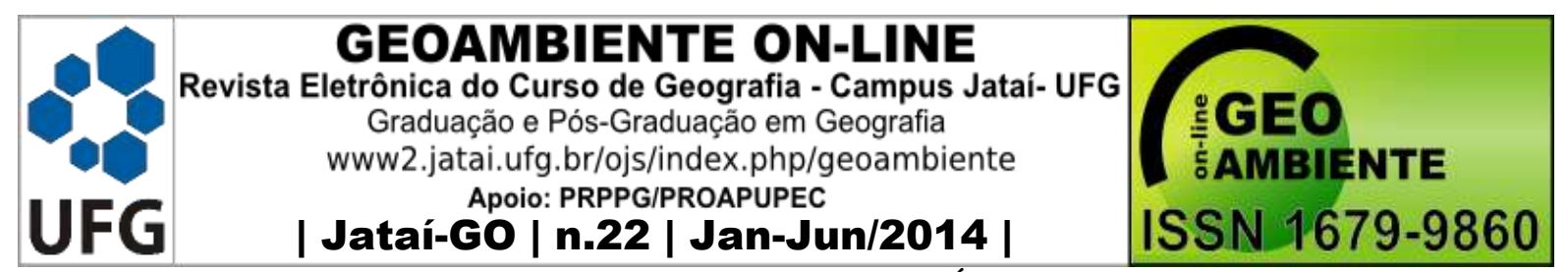

A média encontrada para os autores foi de 5,78. É possível observar que os resultados de Santos \& Santos (2009), Andreoli \& Souza (2006) e García et. al. (2011) apresentaram valores abaixo da média. Entretanto, vale destacar que o trabalho de Santos \& Santos (2009) foi feito em microdestilarias, com produção em escala menor, e o de Garcia et. al. (2011) foi realizado no México, que não é um país que possui o mesmo nível de desenvolvimento, em relação à produção de cana-de-açúcar, que o Brasil.

Figura 3 - Gráfico com a comparação entre os balanços energéticos encontrados para a canade-açúcar.

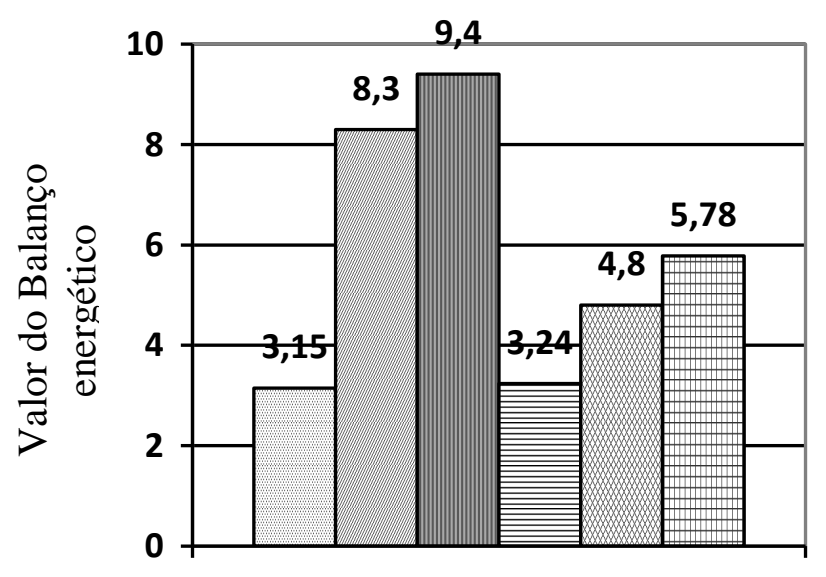

$\square$ Santos \& Santos (2009)
$\square$ Oliveira (2010)
四 Grego (2011)
目Andreoli \& Souza (2006)
G García et al. (2011)
$\square$ Média entre os autores

\subsection{Balanço energético do etanol de fontes amiláceas}

No que diz respeito às fontes amiláceas, a maioria dos trabalhos encontrados sobre o assunto foca o milho como matéria prima para produção de etanol, assim como é a cana no caso das fontes amiláceas. Isso pode se dever ao fato da cana ser a cultura mais utilizada para produção de álcool combustível no Brasil e o milho o ser nos Estados Unidos. De acordo como Grego (2011), os dois países são responsáveis por 75\% da produção mundial de etanol.

No entanto, no caso do milho, a energia líquida produzida em todos os trabalhos analisados foi menor que a da cana-de-açúcar. Segundo Salla et. al (2010), a energia necessária para se produzir um litro de etanol a partir do milho é de 19,7 MJ, enquanto um litro de etanol corresponde a 23,6 MJ, o que nos dá uma relação de 1,2. No trabalho de Oliveira (2010) essa relação ficou em 1,4. Já Andreoli e Souza (2006) e Grego (2011) encontraram balanços energéticos negativos, sendo 1,29:1 $(0,76)$ e 1:0,8 respectivamente.

A figura 4 mostra um gráfico com a comparação entre os balanços energéticos encontrados para as fontes amiláceas (milho e mandioca). 


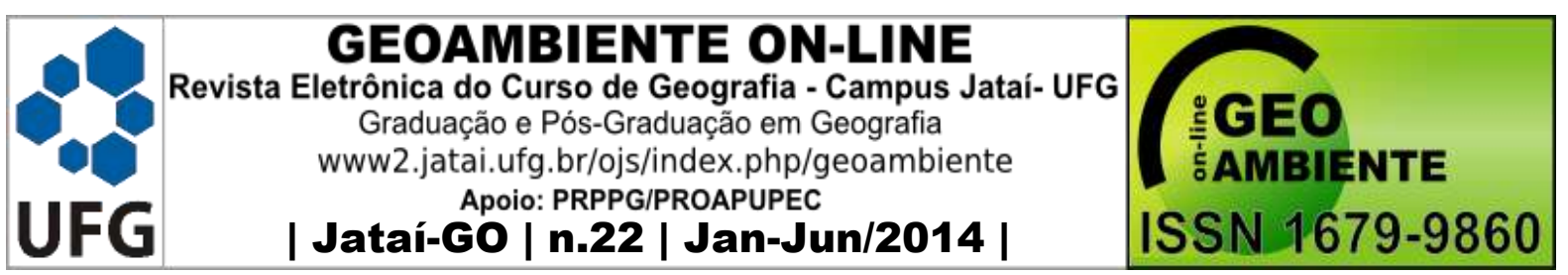

Figura 4 - Gráfico com a comparação entre os balanços energéticos encontrados para as fontes amiláceas.

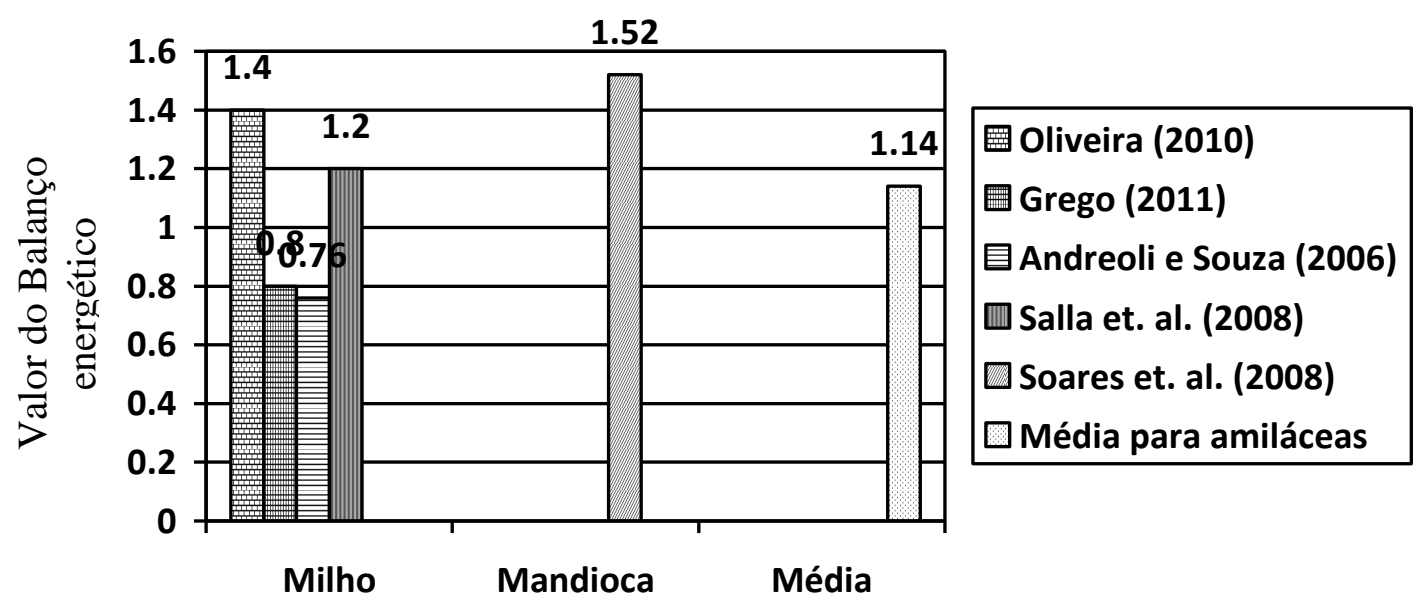

Soares et. al. (2008) realizaram o balanço energético da produção de etanol a partir da mandioca. Segundo os autores, a energia gasta para se cultivar um hectare de mandioca é de 13,47 GJ enquanto a energia necessária para se produzir etanol, considerando uma produtividade de 14 toneladas/ha, é de 11,24 GJ. Somando-se os dois valores temos que a energia total despendida para produção de etanol a partir da mandioca é de 24,71 GJ/ha. Estimando a produtividade de etanol em 120 litros por tonelada e a mesma produtividade agrícola mencionada anteriormente, ambas feitas pelos autores, temos que o etanol obtido em um hectare dessa matéria prima fornece 37,46 GJ, o que gera um balanço energético positivo de 1,52 .

A média encontrada para o balanço energético do etanol para fontes amiláceas, considerando o milho e a mandioca, foi de 1,14 , o que é um balanço positivo (maior que 1), sendo que Grego (2011) e Andreoli \& Souza (2006) obtiveram resultados negativos (menor que 1).

\subsection{Balanço energético do etanol a partir de fontes celulósicas}

$\mathrm{Na}$ literatura não existem muitos trabalhos com o objetivo de se conhecer a energia líquida obtida do etanol a partir de fontes celulósicas. Entretanto, a Empresa Brasileira de Pesquisa Agropecuária - Embrapa (2010) realizou um estudo sobre o assunto, calculando o balanço energético da produção de etanol a partir do bagaço, das pontas e da palha da canade-açúcar. O resultado encontrado foi 9,99, porém é importante se considerar que todas as 


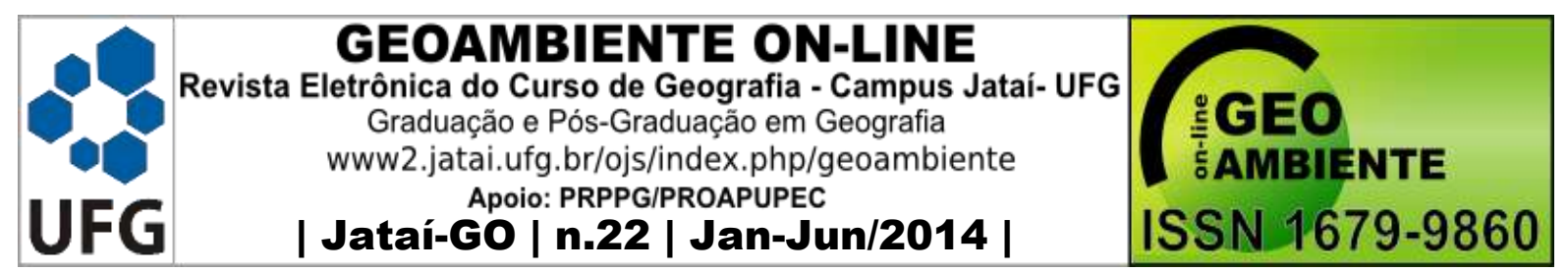

matérias primas mencionadas são resíduos da produção de cana, portanto, não foram considerados gastos energéticos da produção agrícola (cultivo da cana), mas somente o do processo industrial.

A figura 5 apresenta um gráfico com o balanço energético encontrado para as fontes celulósicas.

Figura 5 - Gráfico com o balanço energético encontrado para as fontes celulósicas.

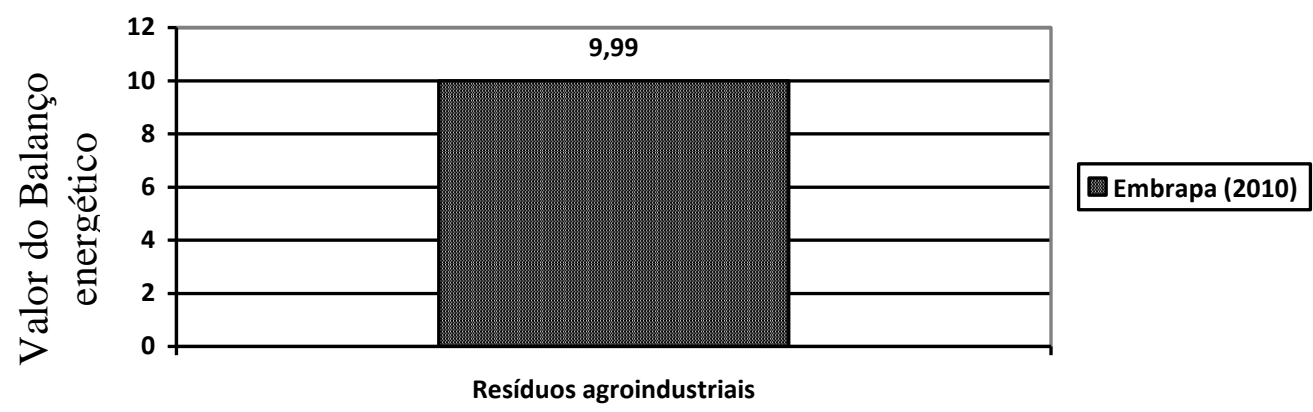

Devido ao fato de ter-se encontrado apenas um trabalho sobre o balanço energético do etanol para fontes celulósicas, não é possível realizar comparações entre os mesmos, no entanto, sabe-se que todas as matérias primas utilizadas para a produção de álcool combustível geram algum resíduo, que pode ser aproveitado no processo após a sacarificação da celulose.

\subsection{Comparação entre os balanços energéticos das diferentes matérias primas}

A tabela 3 apresenta os valores dos balanços energéticos encontrados na literatura para o etanol obtido das diversas fontes.

É possível observar que o maior balanço energético é obtido com a utilização de resíduos para produção de etanol, pois nesse caso, não há gasto de energia na obtenção de matéria-prima. Dentre as culturas agrícolas, a que apresentou maior valor de energia líquida foi a cana-de-açúcar, sendo que o milho, apresentou balanço negativo em alguns casos. A mandioca, no único caso analisado, possui valor maior que o do milho para o balanço energético, porém o mesmo é menor que o da cana de açúcar. 


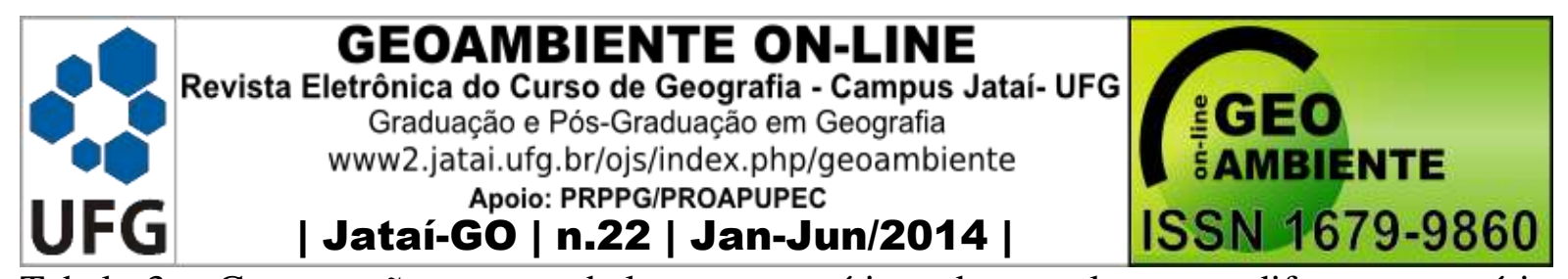

Tabela 3 - Comparação entre os balanços energéticos do etanol para as diferentes matérias primas.

\begin{tabular}{l|c|c|c|c}
\hline \multicolumn{1}{c|}{ Autor (es) } & \multicolumn{3}{c}{ Matéria Prima } \\
\hline & Cana-de-açúcar & Milho & Mandioca & $\begin{array}{c}\text { Resíduos } \\
\text { agroindustriais }\end{array}$ \\
\hline Santos \& Santos (2009) & 3,15 & & & \\
\hline Oliveira (2010) & 8,3 & 1,4 & & \\
\hline Grego (2011) & 9,4 & 0,8 & & \\
\hline Andreoli \& Souza (2006) & 3,24 & 0,76 & & \\
\hline Salla et. al (2010) & & 1,2 & & 9,99 \\
\hline Soares et. al. $(2008)$ & & & 1,52 & \\
\hline Embrapa (2010) & & & & 9,99 \\
\hline García et. al. (2011) & 4,8 & & & \\
\hline Média das fontes & 5,78 & 1,14 (total \\
\end{tabular}

Comparando-se as médias entre os tipos de fontes (sacaríneas, amiláceas e celulósicas) podemos perceber que o balanço energético para as matérias primas sacaríneas apresentou um balanço energético médio de 5,78, que é $407 \%$ maior que a média das amiláceas. Com relação às fontes celulósicas, por ter sido encontrado somente um trabalho com seu balanço de energia, não é possível se fazer inferências, pois o resultado obtido é $217 \%$ maior que o obtido por Santos \& Santos (2009), no entanto é apenas 6,28\% maior que o encontrado por Grego (2011). Por isso, sem uma média entre vários resultados, qualquer comparação seria duvidosa.

\section{CONCLUSÕES}

Por meio da análise do estudo realizado e dos dados coletados na literatura existente, verifica-se que:

$\checkmark$ A cana-de-açúcar é a cultura que mais se destaca dentre as utilizadas atualmente para produção de álcool. Os dados dos diferentes trabalhos consultados apresentam um balanço energético com maior valor, que pode ser ainda maior caso sejam utilizados seus resíduos (bagaço, ponta e palha) para obtenção do etanol.

$\checkmark$ O milho, principal fonte de etanol nos Estados Unidos, apresentou o menor balanço energético entre os estudos analisados, chegando a ser negativo em alguns casos. Sendo que, a média da cana foi $407 \%$ maior que a das fontes amiláceas.

$\checkmark \quad$ O aproveitamento de resíduos agrícolas celulósicos para obtenção de etanol pode ser uma alternativa interessante, pois não demanda energia para produção agrícola, mas pela 


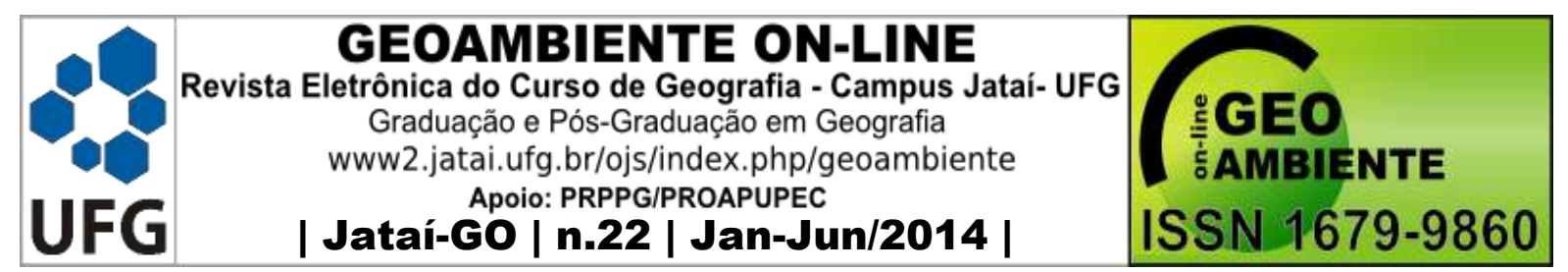

insuficiência de dados torna-se difícil afirmar que seu balanço possa competir com as outras culturas, já que o resíduo é uma variável pouco controlada.

\section{6 - REFERÊNCIAS BIBLIOGRÁFICAS}

ANDREOLI, C. \& SOUZA, S. P. de. Cana-de-açúcar: a Melhor alternativa para Conversão da energia solar e Fóssil em Etanol. Conferência Internacional de AgroEnergia. Disponível em: http://ecen.com/eee59/eee59p/cana_melhor_conversorl.htm. Acesso em: 22/08/2011.

BRAGA, B. et. al. Introdução à Engenharia Ambiental. 2a . Ed. São Paulo: Pearson Prentice Hall, 2005.

EMBRAPA - Empresa Brasileira de Pesquisa Agropecuária. Embrapa Agroenergia apresenta balanço energético do etanol celulósico. Notícia publicada em 01/07/2010. Disponível em: http://www.embrapa.br/imprensa/noticias/2010/junho/4a-semana/embrapa-agroenergiaapresenta-balanco-energetico-do-etanol-celulosico/. Acesso em 23/08/2011.

GARCÍA, C. A.; FUENTES, A.; HENNECKE, A.; RIEGELHAUPT, E.; MANZINI, F. \& MASERA, O. Life-cycle greenhouse gas emissions and energy balances of sugarcane ethanol production in Mexico. Applied Energy v. 88 p. 2088-2097. 2011.

GREGO, L. B. de M. Eficiência energética do etanol e sua produção: Análise comparativa entre Brasil e EUA. Disponível em: https://sistemas.usp.br/siicusp/ cdOnlineTrabalhoVisualizarResumo?numeroInscricaoTrabalho=3695\&numeroEdicao $=18$. Acesso em: 22/08/2011.

LUCON, O. \& GOLDEMBERG, J. Crise financeira, energia e sustentabilidade no Brasil. Revista Estudos Avançados [online]. 2009, vol.23, n.65, pp. 121-130. ISSN 0103-4014.

MACEDO, I. de C.; \& CORTEZ L. A. B. O processamento industrial da cana-de-açúcar no Brasil. In: Uso da biomassa para produção de energia na indústria brasileira. Organizadores: Frank Rosillo-Calle, Serio V. Bajay e Harry Rothman. Tradução por José Dilcio Rocha e Maria Paula G. D. Rocha. Campinas, SP: Editora da UNICAMP, 2005. Cap. 6, p. 247-268.

MACEDO, L. C. H. de. Álcool etílico: da cachaça ao cereal. São Paulo: Ícone, 1993.

MARCOCCIA, R. A participação do etanol em uma nova perspectiva na matriz energética mundial. 2007. 95 p. Dissertação de mestrado - Programa Interunidades de Pós-Graduação em Energia. Universidade de São Paulo. 


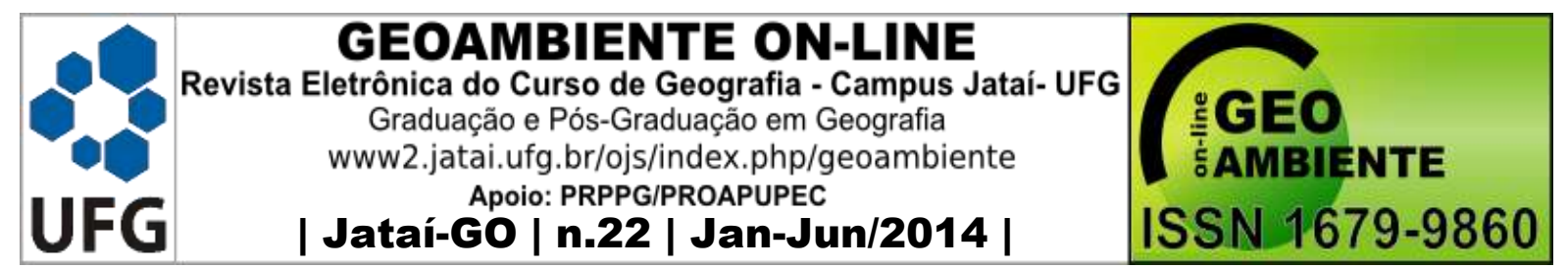

OLIVEIRA, E. C. Balanço energético na produção de álcool da cana-de-açúcar: comparativo com a produção norte americana de etanol por meio da utilização de milho. Trabalho de conclusão de curso, Universidade Estadual de Mato Grosso do Sul. Dourados MS, 2010.

PEREIRA JÚNIOR, N.; FERREIRA, V.; ALVES, D. G. Tecnologia de bioprocessos: ênfase em aproveitamento de materiais amiláceis para produção de etanol. Palmas: UFT/LASPER, 2004. (não publicado).

SAllA, D. A.; FURLANETO, F. de P. B.; CABELlO, C. \& KANTHACK, R. A. D. Estudo energético da produção de biocombustível a partir do milho. Ciência Rural [online]. 2010, vol.40, n.9, pp. 2017-2022. ISSN 0103-8478.

SANTOS, R. E. R e SANTOS, I. A. Análise da viabilidade energética da produção de etanol em microdestilarias. $4^{\circ}$ Congresso Internacional de bioenergia. Curitiba, 2009). Disponível em: http://www.porthuseventos.com.br/site/eventos/2009/ eventobioenergia.com.br/congresso/br/tecnica/RodolfoSantos.pdf. Acesso em 22/08/2011.

SOARES, L. H. de B.; ALVES, B. J. R.; URQUIAGA, S. \& BODDEY, R. M. Balanço energético da produção de bioetanol de mandioca (Manihot esculenta Crantz). Circular técnica 23, Embrapa Agrobiologia, 2008.

SOETAERT, W. \& VANDAMME, E. J. Biofuels. New Delhi, India: Wiley, 2009.

URQUIAGA, A. et al. Produção de biocombustíveis: a questão do balanço energético. Política Agrícola, Brasília, v.14, n.1, p.42-46, 2005. Disponível em: <http:// www. a g r o n e g o c i o s e . c om . b r / a g r / d own / a r t i g o s / Pol_Agr_1_2005_Art06.pdf>.apud: SALLA, D. A.; FURLANETO, F. de P. B.; CABELLO, C. \& KANTHACK, R. A.D. Estudo energético da produção de biocombustível a partir do milho. Ciência Rural [online]. 2010, vol.40, n.9, pp. 2017-2022. ISSN 0103-8478. 